\title{
Superficial Peroneal Nerve Injury Risk During a Semiblind Fasciotomy for Anterior Chronic Exertional Compartment Syndrome of the Leg
}

Citation for published version (APA):

de Bruijn, J. A., van Zantvoort, A. P. M., Hundscheid, H. P. H., Hoogeveen, A. R., Teijink, J. A. W., \& Scheltinga, M. R. (2019). Superficial Peroneal Nerve Injury Risk During a Semiblind Fasciotomy for Anterior Chronic Exertional Compartment Syndrome of the Leg: An Anatomical and Clinical Study. Foot \& Ankle International, 40(3), 343-351. https://doi.org/10.1177/1071100718811632

Document status and date:

Published: 01/03/2019

DOI:

10.1177/1071100718811632

Document Version:

Publisher's PDF, also known as Version of record

\section{Document license:}

Taverne

Please check the document version of this publication:

- A submitted manuscript is the version of the article upon submission and before peer-review. There can be important differences between the submitted version and the official published version of record.

People interested in the research are advised to contact the author for the final version of the publication, or visit the DOI to the publisher's website.

- The final author version and the galley proof are versions of the publication after peer review.

- The final published version features the final layout of the paper including the volume, issue and page numbers.

Link to publication

\footnotetext{
General rights rights.

- You may freely distribute the URL identifying the publication in the public portal. please follow below link for the End User Agreement:

www.umlib.nl/taverne-license

Take down policy

If you believe that this document breaches copyright please contact us at:

repository@maastrichtuniversity.nl

providing details and we will investigate your claim.
}

Copyright and moral rights for the publications made accessible in the public portal are retained by the authors and/or other copyright owners and it is a condition of accessing publications that users recognise and abide by the legal requirements associated with these

- Users may download and print one copy of any publication from the public portal for the purpose of private study or research.

- You may not further distribute the material or use it for any profit-making activity or commercial gain

If the publication is distributed under the terms of Article $25 \mathrm{fa}$ of the Dutch Copyright Act, indicated by the "Taverne" license above, 


\title{
Superficial Peroneal Nerve Injury Risk During a Semiblind Fasciotomy for Anterior Chronic Exertional Compartment Syndrome of the Leg: An Anatomical and Clinical Study
}

Foot \& Ankle International 2019, Vol. 40(3) 343-35।

(C) The Author(s) 2018

Article reuse guidelines: sagepub.com/journals-permissions DOI: $10.1177 / 1071100718811632$ journals.sagepub.com/home/fai

\author{
Johan A. de Bruijn, MD, MSc', Aniek P. M. van Zantvoort, MD', \\ Henricus Pieter Hubert Hundscheid, BSc', Adwin R. Hoogeveen, MD, PhD' \\ Joep A. W. Teijink, MD, PhD $^{3,4}$, and Marc R. Scheltinga, MD, PhD'
}

\begin{abstract}
Background: Up to $8 \%$ of patients who underwent a fasciotomy for leg anterior chronic exertional compartment syndrome (ant-CECS) report sensory deficits suggestive of iatrogenic superficial peroneal nerve (SPN) injury. In the current study we aimed to thoroughly assess the risk of SPN injury during a semiblind fasciotomy of the anterior compartment using 2 separate approaches.

Methods: A modified semiblind fasciotomy of the anterior compartment was performed via a longitudinal 2-cm skin incision $2 \mathrm{~cm}$ lateral of the anterior tibial crest halfway along the line fibular head-lateral malleolus both in cadaver legs and in patients with ant-CECS. In the cadaver legs, the skin was removed after the procedure and possible SPN injuries and spatial relationships between the SPN and the opened fascia were studied. Between January 2013 and December 2016, 64 ant-CECS patients who underwent a fasciotomy of the anterior compartment were prospectively followed. latrogenic SPN injuries were assessed using questionnaires and physical examinations.

Results: Macroscopic SPN nerve injury was not observed in any of the 9 cadaver legs. In 8 specimens, the SPN was located at least $5 \mathrm{~mm}$ posterolateral to the opened fascia. In I specimen, an undamaged SPN branch crossed the operative field in a ventral plane. De novo sensory deficits suggestive for iatrogenic SPN injury were not observed in any of the 64 patients ( 20 legs; 36 females; median age, 22 years) who underwent a fasciotomy of the anterior compartment.

Conclusion: The proposed semiblind fasciotomy for treatment of ant-CECS was not associated with SPN injury in either the cadaveric study or our clinical series.

Level of Evidence: Level IV, case series.

Keywords: CECS, fasciotomy, anterior compartment, superficial peroneal nerve

Chronic exertional compartment syndrome (CECS) is an exercise-induced condition that is predominantly found in the tibialis anterior compartment (ant-CECS). ${ }^{7,22,24}$ Conservative treatment may offer relief, but a substantial portion of patients are ultimately operated on. ${ }^{3}$ Results of a fasciotomy for ant-CECS are generally satisfactory, with success rates between $52 \%$ and $100 \% .^{8,13,25,35}$ However, complications associated with surgery, ranging from simple hematomas to long-lasting disabilities, are not unusual. ${ }^{12,29}$ Injury of the superficial peroneal nerve (SPN) is a troublesome complication incidentally seen after a fasciotomy of the

'Department of Surgery, Máxima Medical Center, Veldhoven, the Netherlands

${ }^{2}$ Department of Sports Medicine, Máxima Medical Center, Veldhoven, the Netherlands

${ }^{3}$ Department of Surgery, Catherina Hospital, Eindhoven, the Netherlands ${ }^{4}$ Department of Epidemiology, CAPHRI Research School, Maastricht University, Maastricht, the Netherlands

\section{Corresponding Author:}

Johan A. de Bruijn, MD, MSc, Department of Surgery, Máxima Medical Center, de Run 4600, P.O. Box 7777, Veldhoven, 5504 DB,

the Netherlands.

Email: CECS.resurge@mmc.nl
\end{abstract}


anterior (and lateral) compartment. ${ }^{26,29}$ Persistent pain, tingling, and/or reduced skin sensation on the dorsum of the foot and the anterolateral ankle suggesting iatrogenic SPN injury are found in up to $8 \%$ of the patients who underwent a fasciotomy of the anterior compartment. ${ }^{6,23,27,28,31,33,34}$

Several operative techniques are currently available for the treatment of ant-CECS. A popular approach is a "semiblind fasciotomy" that was introduced in the late 1980s. This technique is fast and requires a skin incision of only $2-3 \mathrm{~cm}$ through which a small fascial cut is made that is extended subcutaneously toward the ankle and the fibular head using a fasciotome. As direct visual contact with the fasciotome's tip is largely absent during this procedure, SPN injury may occur. To overcome this complication, others have used larger skin incisions ${ }^{4,11}$ or even multiple incisions. ${ }^{18,27}$ More recently, the assistance of an endoscope was advocated. ${ }^{20}$ True comparative studies are absent; hence, the optimal operative technique that is associated with a minimal risk of SPN injury has yet to be determined.

As a referral center, we perform a substantial number of semiblind anterior releases. In January 2013 we adopted a technique using a modified fasciotome in our hospital. ${ }^{5}$ If this technique is safe, it may provide a cost-effective and simple alternative for an endoscope-assisted fasciotomy of the leg anterior compartment. The aim of the present study was to accurately determine the risk of iatrogenic SPN injury using this modified semiblind technique. Therefore, we used 2 separate approaches. We performed a fasciotomy of the anterior compartment in human cadavers to objectively assess the risk for SPN injury. We also searched for SPN injuries in a prospectively followed cohort of antCECS patients who underwent an anterior fasciotomy in our center.

\section{Methods}

\section{Cadaver Study}

We used 9 fresh frozen legs of 5 individuals. None of these were previously used for research purposes or operative training, and visible external scars suggesting previous major trauma or surgery were absent. One leg had a small skin defect over the anterolateral aspect, probably the result of postmortem freezing and storage (specimen 9, Figure 1A).

A fasciotomy of the anterior compartment of the leg was performed with the FascioMax system at Van Straten Medical, Nieuwegein, the Netherlands. This reusable device was designed and constructed in our hospital. In short, the novel instrument consisted of 2 parts: a thin fasciotome with a vertical knife and a speculum-type steel device with a handle, lock, and 2 sturdy semicircular blades. These sturdy blades could be opened or closed, thus forming a $30-\mathrm{cm}-$ long, 5-mm-wide hollow tube that allows for insertion of the fasciotome. The device itself, including its mode of action, was previously described in detail. ${ }^{5}$ The fibular head and lateral malleolus were marked and a 2-cm longitudinal skin incision was made $2-3 \mathrm{~cm}$ lateral to the lateral margin of the tibial crest, exactly halfway along the line between these landmarks (Figure 1A). From this location the anterior compartment was easily accessible. However, as the intramuscular septum was located more laterally, this location was not suitable for a fasciotomy of the lateral compartment. Next, the crural fascia was bluntly freed of overlying fatty tissue and a 1.5 - to $2-\mathrm{cm}$ fascial incision was made (Figure 1B). A 2-cm-wide subcutaneous tunnel immediately superficial to the crural fascia was created toward the knee joint and the ankle joint (Figure 1C and D). The lower blade of the speculum was inserted immediately underneath the tibialis anterior muscle fascia and carefully advanced toward the knee (Figure 1E). By doing so, the upper blade automatically followed through the subcutaneous tunnel superficial to the fascia. By closing the handle, the crural fascia was firmly grasped between the 2 blades. Once a correct position was confirmed by transcutaneous palpation, the thin rod with the vertical knife was advanced into the tube toward the end, thus cutting the fascia in a controlled fashion (Figure 1F). A 4- to $5-\mathrm{cm}$ portion of distal crural fascia toward the ankle joint was cut under direct visual inspection using a small retractor and scissors. The lateral compartment was not opened.

Once the fasciotomy was performed, skin and subcutaneous tissue were removed, the SPN was carefully inspected for macroscopic damage, and distances between SPN and cleaved fascia were measured. These measurements were only performed at the distal portion of the SPN, where the nerve is thought to surface through the fascia and thus is at risk of injury. Additional measured parameters were completeness and length of the fasciotomy and the SPN course. The latter was to clarify the relation between the SPN and the opened fascia. By studying only 9 legs, the intention of the study was to describe a proof of concept but not to ascertain all possible anatomical SPN variants.

\section{Patient Study}

The Department of Sports Medicine of Máxima Medical Center in Veldhoven, the Netherlands is a referral center for exercise-induced leg entities. Patients were diagnosed with an ant-CECS if history and physical examination were suggestive of a CECS and intracompartmental pressure (ICP) was elevated in the anterior compartment. ICP was termed elevated if it exceeded one or more of the following cutoff values: $15 \mathrm{~mm}$ $\mathrm{Hg}$ at rest, $30 \mathrm{~mm} \mathrm{Hg} 1$ minute after provocation, or $20 \mathrm{~mm} \mathrm{Hg}$ 5 minutes after provocation. ${ }^{21}$ A detailed description of the diagnostic process was previously published. ${ }^{5}$

Starting January 2013, each patient who was evaluated for CECS in our institution was asked to complete a 

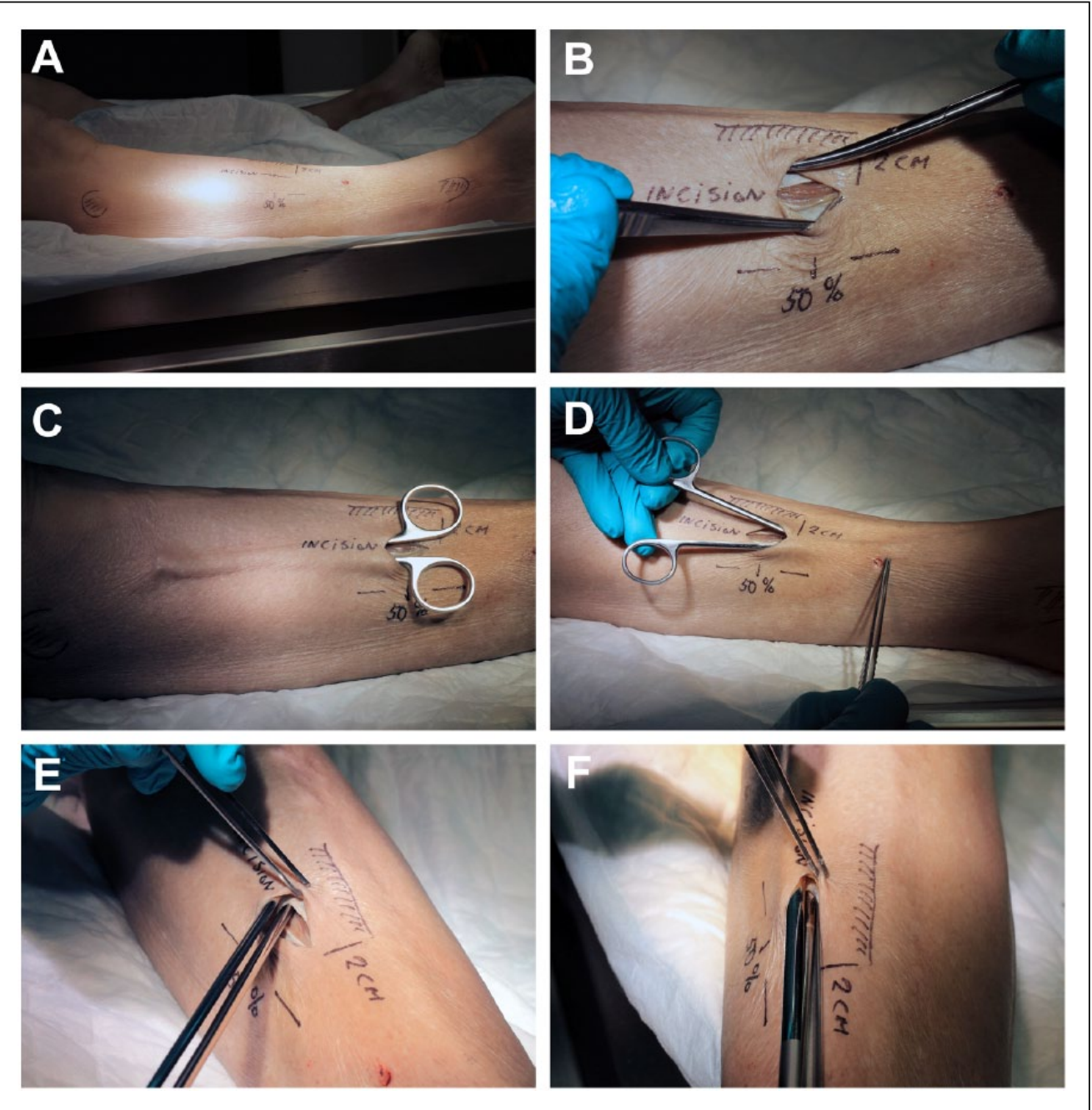

Figure I. Consecutive steps of a semiblind fasciotomy of the anterior compartment in cadavers. (A) Anatomical landmarks (fibular head and lateral malleolus) and the location of the incision are marked. Note the small skin defect just distal to the incision. (B) The crural fascia was bluntly freed of overlying fatty tissue and a $1.5-$ to $2-\mathrm{cm}$ fascial incision was made. (C and D) A subcutaneous tunnel immediately superficial to the fascia is bluntly created toward the knee and ankle joint using spreading movements of scissors. (E) The lower blade of the speculum is inserted into the tibialis anterior muscle compartment and carefully advanced toward the knee just underneath the crural fascia. (F) After confirmation of the correct position by transcutaneous palpation, closing the handle fixates the fascia and the thin rod with the vertical knife is advanced into the tube toward the end.

questionnaire. They scored intensity and frequency of leg pain, tightness, cramps, muscle weakness, and altered sensibility/tingling at rest and during exercise using a verbal rating scale (VRS). A similar questionnaire was completed 3-6 months postoperatively (short term) and at least 12 months postoperatively (long term). Some ant-CECS patients were referred only for diagnostics and underwent treatment in their referring hospital. Patients who opted for operative treatment in our center were counseled and treated by the senior author (M.S.). The operative procedure for the anterior fasciotomy was similar to the method described above (cadaver study). Additional fasciotomies of the lateral and/or deep flexor compartment were only performed if a multicompartmental CECS was found during ICP measurements. These were performed via additional skin incisions, either during the initial procedure or in an additional operation. The lateral compartment was not opened in patients with isolated ant-CECS, as this possibly adds risk and morbidity while clinical results may not be improved. ${ }^{28,32}$

\section{Postoperative Outpatient Evaluation}

Each patient was invited to our outpatient clinic 2-4 weeks after the fasciotomy. They were asked whether they experienced new alterations in skin sensation or a tingling feeling in 


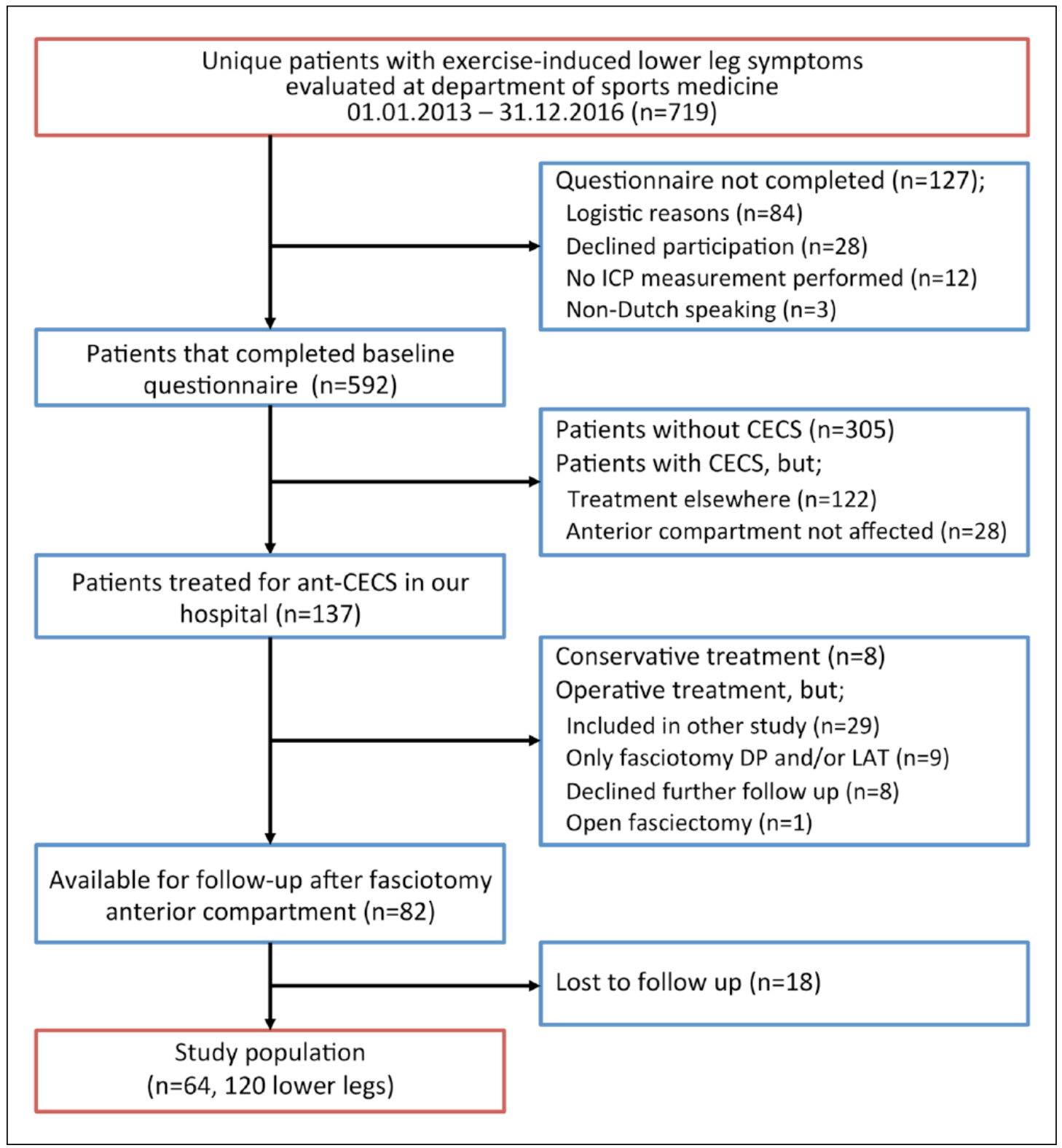

Figure 2. Patient selection. CECS, chronic exertional compartment syndrome; DP, deep flexor compartment; ICP, intracompartmental pressure measurement; LAT, lateral compartment.

the leg. Anterolateral leg skin sensation was tested using light touch with gauze soaked in alcohol or swabs. We defined iatrogenic SPN injury as reduced skin sensation and/or tingling in the lower lateral portions of the leg and/or dorsum of the foot that was not present during the preoperative outpatient visit. In addition, we termed patient-reported newly acquired continuous altered skin sensibility or tingling as suggestive of SPN injury. When patients reported findings suggestive of SPN that were not noticed during the postoperative outpatient visit, they were invited for a second outpatient visit.

\section{Patient Selection}

Between January 2013 and December 2016, 719 individuals were evaluated for CECS at our department of sports medicine (Figure 2). A total of 137 patients were eligible for the present study as they were diagnosed with ant-CECS and treated in our hospital. Patients were excluded if they did not undergo a fasciotomy of the anterior compartment using the FascioMax technique $(n=18)$; were included in a randomized controlled trial $(n=29$, all patients aged 18 years or 
older with isolated bilateral ant-CECS, Dutch trial registry number NTR4274); or declined further follow-up $(n=8)$. As 18 patients were lost to follow-up, the study population consisted of 64 patients. These patients all underwent a fasciotomy of the anterior compartment, had completed preoperative and postoperative questionnaires, and had visited the outpatient clinic after surgery at least once.

\section{Statistics and Ethics}

SPSS Statistics, Windows version 22.0.0.0 (IBM Corp., Armonk, NY), was used for all analyses. Data are shown as mean ( $\pm \mathrm{SD})$ when normally distributed, or as median (range) when not normally distributed. The Radboud University Department of Anatomy provided us with the cadaveric specimens. All deceased patients had given consent for scientific usage of their bodies after their death. All procedures performed in this study were in accordance with the ethical standards of our institutional research committee and with the Declaration of Helsinki. The local medical ethical committee judged that the rules laid down in the Medical Research Involving Human Subjects Act (WMO) did not apply to the study protocol. No outside funding was used.

\section{Results}

\section{Cadaver Study}

Characteristics of the deceased patients and measured distances are depicted in Table 1. The SPN was not visible via the 2-cm skin incision in any of the 9 legs. The introduction of the fasciotome occurred smoothly and always at the first attempt. The median length of the released fascia was 212 $\mathrm{mm}$ (range, 175-235). The median distance between the fibular head and the released fascia was $48 \mathrm{~mm}$ (range, 25-110), and the median distance between the lateral malleolus and the released fascia was $105 \mathrm{~mm}$ (range, 60-125). One fasciotomy was incomplete as a proximal portion of the fascia was still intact (specimen 1). This failure may have been due to a suboptimal quality of the cadaver's crural fascia as multiple fascial defects were seen after removal of the skin.

Macroscopic SPN injury was not observed. In all 9 legs, the SPN originated from the common peroneal nerve proxi$\mathrm{mal}$ in the lateral compartment. In 6/9 legs, the SPN exited the lateral compartment through the crural fascia and continued subcutaneously toward the ankle joint. In these 6 specimens, the nerve remained lateral of the released fascia by at least $7 \mathrm{~mm}$ (Figure 3A, Table 1). In the remaining 3 legs, the SPN branched in the lateral compartment; one branch remained in the lateral compartment, whereas the other branch exited the lateral compartment through the crural fascia. In 2 of these legs (specimens 4 and 7), this medial subcutaneous branch coursed at least $5 \mathrm{~mm}$ lateral to the released fascia. However, in 1 leg (specimen 3) the SPN was potentially at risk as its subcutaneous branch crossed the opened fascia in a ventral plane (Figure 3B). Even though the nerve crossed the released fascia, it was macroscopically intact.

\section{Patient Study}

Of the 64 included patients, 36 were female (56\%) and the median age was 22 years (range, 15-65). A total of 62 patients participated in sports (socially, $n=25$; locally competitive, $n=23$; nationally competitive, $n=13$; internationally competitive, $n=1)$. Most patients were engaged in running $(n=17)$ or ball sports $(n=35)$. Symptoms had started 29 months prior to analysis (median range, 3-360) and resulted in practicing sports with complaints $(n=7)$, lowering the level/intensity $(n=19)$, choosing a different sport $(n=4)$, or quitting sports altogether $(n=32)$. A bilateral fasciotomy was performed in 56 patients, amounting to a total of 120 operated legs. In 55\% of the patients (35/64), only the anterior compartment was decompressed. The remaining 29 patients (45\%) also underwent a fasciotomy of the deep flexor compartment $(n=18)$, lateral compartment $(n=9)$, or both the deep flexor and the lateral compartment $(n=2)$. One ant-CECS patient was also diagnosed with a concurrent distal SPN entrapment and underwent a release of the SPN via a separate incision just above the ankle joint. The SPN was not seen in any of the patients during the procedure. Perioperative complications such as bleeding or the necessity to extend the 2-cm incision were not encountered.

During the postoperative visit, we identified 5 patients with postoperative sensory complaints and/or abnormalities during neurological examination of the operated legs (Table 2). Four of these 5 patients also reported continuous sensory leg complaints in the operated legs. In 3 of these 5 patients, sensory deficits were already documented during the preoperative outpatient clinic visit. Surgery had not altered these preexisting sensory complaints. New-onset sensory deficits were diagnosed in the 2 remaining patients. One patient, who had undergone combined anterior and deep flexor muscle decompression, reported skin numbness of a medial portion of the distal leg that was ascribed to an injured side branch of the saphenous nerve. The second patient had reduced skin sensibility of a $9 \times 4-\mathrm{cm}$ area of a proximal portion of the left lateral leg. This hyposensitivity may have been caused by injury of a proximal side branch of the sural nerve. However, skin sensibility of his distal leg and foot was unaltered, indicating an intact SPN. Therefore, none of the 120 legs displayed new-onset sensory deficits suggestive of iatrogenic SPN injury. 
Table I. Characteristics and Measurements of the Cadaveric Legs.

\begin{tabular}{|c|c|c|c|c|c|c|c|c|c|}
\hline Specimen & 1 & 2 & 3 & 4 & 5 & 6 & 7 & 8 & 9 \\
\hline Patient & $A$ & A & B & B & C & $\mathrm{C}$ & $\mathrm{D}$ & $\mathrm{D}$ & $\mathrm{E}$ \\
\hline Age at death, $y$ & 85 & 85 & 92 & 92 & 83 & 83 & 92 & 92 & 70 \\
\hline Gender & Male & Male & Male & Male & Male & Male & Female & Female & Female \\
\hline Weight, kg & 61 & 61 & 81 & 81 & 83 & 83 & 44 & 44 & 81 \\
\hline Length, m & I.77 & I.77 & 1.78 & 1.78 & 1.78 & 1.78 & 1.59 & 1.59 & 1.66 \\
\hline Leg & Right & Left & Right & Left & Right & Left & Right & Left & Right \\
\hline $\begin{array}{l}\text { Distance from fibular } \\
\text { head to the lateral malleolus, } \\
\mathrm{mm}\end{array}$ & 380 & 385 & 355 & 350 & 370 & 370 & 350 & 360 & 350 \\
\hline $\begin{array}{l}\text { Distance from fibular head to } \\
\text { the skin incision, } \mathrm{mm}\end{array}$ & 180 & 182 & 168 & 165 & 175 & 175 & 165 & 170 & 165 \\
\hline $\begin{array}{l}\text { Length of cleaved } \\
\text { fascia, } \mathrm{mm}\end{array}$ & 175 & 235 & 212 & 215 & 220 & 195 & 195 & 206 & 220 \\
\hline $\begin{array}{l}\text { Length of cleaved fascia/length } \\
\text { of fibular head to the lateral } \\
\text { malleolus, } \%\end{array}$ & 46 & 61 & 60 & 61 & 59 & 53 & 56 & 57 & 63 \\
\hline Fasciotomy complete & No & Yes & Yes & Yes & Yes & Yes & Yes & Yes & Yes \\
\hline $\begin{array}{l}\text { Distance from fibular head to } \\
\text { cleaved fascia, } \mathrm{mm}\end{array}$ & 110 & 65 & 25 & 45 & 48 & 55 & 48 & 45 & 55 \\
\hline $\begin{array}{l}\text { Distance from lateral } \\
\text { malleolus to cleaved fascia, } \\
\mathrm{mm}\end{array}$ & 125 & 82 & 115 & 100 & 88 & 120 & 105 & 115 & 60 \\
\hline Course SPN ${ }^{\mathrm{a}}$ & I & I & 3 & 2 & I & I & 2 & I & I \\
\hline $\begin{array}{l}\text { Distance from compartmental } \\
\text { exit SPN to lateral malleolus, } \\
\mathrm{mm}\end{array}$ & 100 & 115 & 160 & 100 & 90 & 105 & 160 & 150 & 107 \\
\hline Macroscopic injury SPN & No & No & No & No & No & No & No & No & No \\
\hline $\begin{array}{l}\text { Distance from the most distal } \\
\text { point cleaved fascia to SPN, } \\
\mathrm{mm}\end{array}$ & Subfascial & 11 & 0 & 22 & Subfascial & Subfascial & 9 & 16 & 18 \\
\hline $\begin{array}{l}\text { Distance from cleaved fascia } \\
20 \mathrm{~mm} \text { proximal (from most } \\
\text { distal) to SPN, mm }\end{array}$ & Subfascial & 13 & 0 & Subfascial & Subfascial & Subfascial & 7 & 10 & 18 \\
\hline $\begin{array}{l}\text { Distance from cleaved fascia } \\
40 \mathrm{~mm} \text { proximal (from most } \\
\text { distal) to SPN, mm }\end{array}$ & Subfascial & 13 & 0 & Subfascial & Subfascial & Subfascial & 5 & 7 & 17 \\
\hline $\begin{array}{l}\text { Distance from cleaved fascia } \\
60 \mathrm{~mm} \text { proximal (from most } \\
\text { distal) to SPN, mm }\end{array}$ & Subfascial & Subfascial & Subfascial & Subfascial & Subfascial & Subfascial & Subfascial & Subfascial & Subfascial \\
\hline
\end{tabular}

Abbreviation: SPN, superficial peroneal nerve.

${ }^{a}$ Course superficial peroneal nerve: I, does not branch and leaves lateral compartment through crural fascia, continues laterally in distal direction while subcutaneous; 2 , branches once in lateral compartment, I branch remains in the lateral compartment, the subcutaneous branch continues laterally after piercing the crural fascia; 3, one SPN branch is intracompartmental, its subcutaneous branch continues in the anterior direction.

\section{Discussion}

The aim of the current study was to assess the risk of iatrogenic SPN injury during a modified semiblind fasciotomy of the anterior compartment of the leg. We did not find macroscopic damage of the SPN in any of the 9 cadaveric legs, although a branch of the SPN was potentially at risk in 1 specimen as it crossed the operative field. Furthermore, signs of iatrogenic SPN injury were not identified in a prospective cohort of 64 patients who had undergone a fasciotomy of the anterior compartment in 120 legs. Therefore, this modified semiblind technique carried a low risk of SPN injury during a fasciotomy of the anterior compartment.

Due to its location, the SPN is at risk during a fasciotomy of the anterior compartment. Its course and anatomical variations were previously studied in cadavers. ${ }^{1,2}$ The SPN consistently originates in the proximal lateral compartment of the leg as a branch of the common peroneal nerve. ${ }^{1}$ Toward the ankle joint its course is highly 

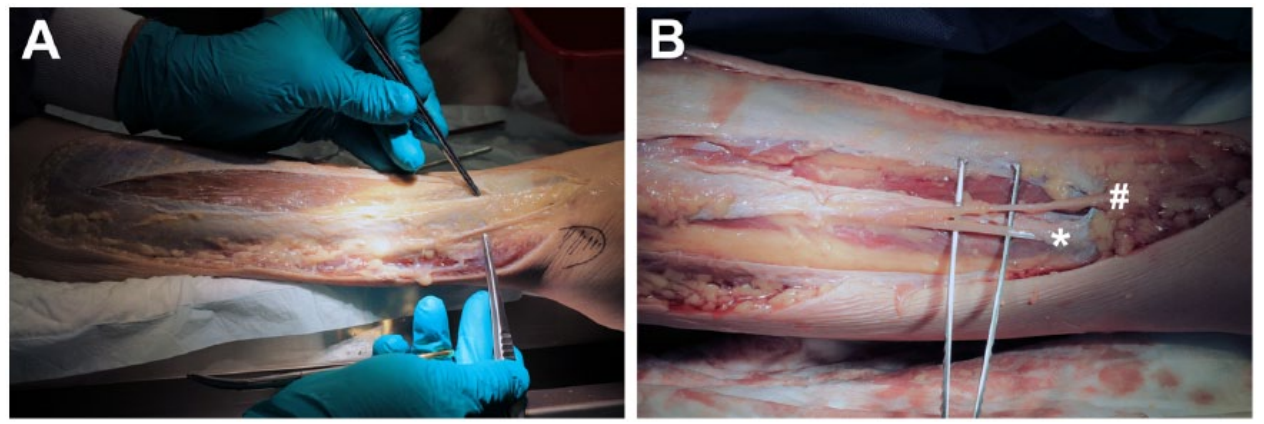

Figure 3. Superficial peroneal nerve (SPN) after skin removal following an anterior compartment fasciotomy in a cadaver leg. (A) The distance between the opened fascia (left-hand forceps) and the SPN (right-hand forceps) was measured. (B) The SPN branched in the lateral compartment in specimen 3. One branch continued in the lateral compartment $(*)$, while the other exited the lateral compartment and crossed the released crural fascia in a ventral plane (\#). Although at risk, this branch was not damaged.

Table 2. Patients With Sensory Deficits After Surgery, Either Self-Reported or Diagnosed During Outpatient Visit.

\begin{tabular}{|c|c|c|}
\hline ID & Source & Findings \\
\hline \multirow[t]{6}{*}{62} & Patient questionnaire & Reported newly acquired continuous sensory deficits after surgery \\
\hline & Outpatient clinic, preoperative & $\begin{array}{l}\text { Tingling and reduced sensibility in dorsal side foot during palpation of } \\
\text { anterior compartment }\end{array}$ \\
\hline & Procedure & Left tibialis anterior fasciotomy \\
\hline & Outpatient clinic, postoperative & Unchanged tingling and reduced sensibility \\
\hline & Additional examinations & Electromyography: reduced conductivity SPN \\
\hline & Conclusion & Peroneal entrapment syndrome, successfully treated with surgical release \\
\hline \multirow[t]{6}{*}{203} & Patient questionnaire & Reported newly acquired continuous sensory deficits after surgery \\
\hline & Outpatient clinic, preoperative & No sensory deficits \\
\hline & Procedure & Bilateral tibialis anterior fasciotomy \\
\hline & Outpatient clinic, postoperative & $\begin{array}{l}\text { Reduced sensibility in strip }(9 \times 4 \mathrm{~cm}) \text { of proximal left lower leg, normal } \\
\text { sensibility distal portion }\end{array}$ \\
\hline & Additional examinations & None \\
\hline & Conclusion & Injury to proximal side branch of the sural nerve \\
\hline \multirow[t]{6}{*}{266} & Patient questionnaire & Reported no newly acquired continuous sensory deficits after surgery \\
\hline & Outpatient clinic, preoperative & Tingling in lateral left lower leg and toes \\
\hline & Procedure & Bilateral anterior + deep flexor fasciotomy \\
\hline & Outpatient clinic, postoperative & Unchanged tingling in lateral left lower leg and toes \\
\hline & Additional examinations & $\begin{array}{l}\text { Intracompartmental pressure measurement: elevated pressure in lateral } \\
\text { compartment }\end{array}$ \\
\hline & Conclusion & Sensory deficits due to CECS of the lateral compartment \\
\hline \multirow[t]{6}{*}{268} & Patient questionnaire & Reported newly acquired continuous sensory deficits after surgery \\
\hline & Outpatient clinic, preoperative & Reduced sensibility in sole and lateral side right foot \\
\hline & Procedure & Right tibialis anterior + deep flexor fasciotomy \\
\hline & Outpatient clinic, postoperative & Unchanged reduced sensibility in sole and lateral side right foot \\
\hline & Additional examinations & None \\
\hline & Conclusion & Preexisting sensory deficits not suspect for operative SPN injury \\
\hline \multirow[t]{6}{*}{422} & Patient questionnaire & Reported newly acquired continuous sensory deficits after surgery \\
\hline & Outpatient clinic, preoperative & No sensory deficits \\
\hline & Procedure & Bilateral anterior + deep flexor fasciotomy \\
\hline & Outpatient clinic, postoperative & Reduced sensibility in medial distal right lower leg \\
\hline & Additional examinations & None \\
\hline & Conclusion & Injury of the saphenous nerve \\
\hline
\end{tabular}

Abbreviations: CECS, chronic exertional compartment syndrome; SPN, superficial peroneal nerve. 
variable and the nerve may be at risk if it approaches the operative field. In our current small series, the SPN was located safely posterolateral to the released fascia in $8 / 9$ legs. In 1, however, an SPN side branch crossed the released fascia in a ventral plane. Although this branch was not damaged, an SPN is clearly at risk in patients with this SPN variant during a fasciotomy of the anterior compartment.

Several operative techniques have been advocated for treating ant-CECS. Approaches vary in terms of invasiveness, efficacy, and risk of complications, including SPN injury. A completely open technique offers direct visual contact, but at the expense of a rather large skin incision. ${ }^{19}$ Invasiveness can be reduced by using 2 or 3 smaller incisions ${ }^{7,26}$ or by using a fasciotome through a single 2-cm skin incision. ${ }^{9}$ SPN injury has been reported after both open and semiblind techniques. ${ }^{4,8,10,31,34}$ More recently, the use of endoscopic assistance to enhance visibility without increasing incisional length has been reported. ${ }^{16}$ Early reports of endoscope-assisted fasciotomies suggest that the risk of SPN injury is reduced compared with a conventional semiblind technique. ${ }^{14,15}$ However, clinical results were not superior to those of non-endoscopic-assisted techniques, and endoscopeassisted fasciotomies are likely to be more expensive and time-consuming. ${ }^{16,17,30,36}$ Therefore, it is still questionable whether the increased visibility outweighs the disadvantages.

In the present cadaver and human study, the SPN was not injured during a fasciotomy of the anterior compartment. These optimal results may be explained in several ways. First, the proposed point of introduction of the fasciotome was safe. The $2-\mathrm{cm}$ skin incision, located $2-3 \mathrm{~cm}$ lateral to the tibial crest and exactly halfway between the fibular head and lateral malleolus, offered optimal visibility of the area where the SPN was most likely to surface through the crural fascia. ${ }^{2}$ Moreover, by using this location, the fasciotomy toward the ankle joint was executed under direct visual contact, preventing injury to an SPN variant that crosses the operative area. Second, this location allowed for a safe and reliable release of much larger proximal portions of the crural fascia. The FascioMax system likely separated the fascia from its overlying subcutaneous tissue and may thus have minimized the risk of nerve injury during the fasciotomy toward the knee when direct visual contact was lacking. However, it may have not been possible to avoid injury of all small, clinically less relevant proximal sensory branches, as illustrated by one patient (ID 203, Table 2).

The current study has limitations. The cadaver study entailed a limited number of specimens and alternative anatomical SPN variants are likely to exist. However, we feel confident that the proposed technique minimized the risk of SPN injury during a fasciotomy of the anterior compartment, as was illustrated by the absence of SPN injuries. Also, the clinical study entailed a limited number (64 patients, 120 legs) of selected cases. However, we believe that the volume of this case series was sufficient for the current goal, which was to evaluate the number of SPN injuries after a fasciotomy of the anterior compartment. The presented modified approach will be compared with a standard-of-care operative treatment in a currently ongoing randomized controlled trial. The strengths of the study were the use of both anatomical and clinical data. Moreover, by using data from outpatient clinic visits and patientreported outcomes, the risk of missed SPN injuries was minimized.

\section{Conclusion}

The present study demonstrated that the proposed modified semiblind fasciotomy for the treatment of ant-CECS was not associated with iatrogenic SPN injury. This method appears to be a simple and safe alternative for open or endoscope-assisted techniques.

\section{Acknowledgments}

The Department of Anatomy, Radboud University, Nijmegen, the Netherlands is acknowledged for facilitating the cadaver study.

\section{Declaration of Conflicting Interests}

The author(s) declared no potential conflicts of interest with respect to the research, authorship, and/or publication of this article. ICMJE forms for all authors are available online.

\section{Funding}

The author(s) received no financial support for the research, authorship, and/or publication of this article.

\section{References}

1. Adkison DP, Bosse MJ, Gaccione DR, Gabriel KR. Anatomical variations in the course of the superficial peroneal nerve. J Bone Joint Surg Am. 1991;73(1):112-114.

2. Blair JM, Botte MJ. Surgical anatomy of the superficial peroneal nerve in the ankle and foot. Clin Orthop Relat Res. 1994;305:229-238.

3. Brennan FH, Kane SF. Diagnosis, treatment options, and rehabilitation of chronic lower leg exertional compartment syndrome. Curr Sports Med Rep. 2003;2(5):247-250.

4. Cook S, Bruce G. Fasciotomy for chronic compartment syndrome in the lower limb. ANZ J Surg. 2002;72(10):720-723.

5. de Bruijn JA, van Zantvoort APM, Winkes MB, et al. Feasibility and safety of an operative tool for anterior chronic exertional compartment syndrome treatment. Foot Ankle Int. 2015;36(12):1475-1482.

6. de Fijter WM, Scheltinga MR, Luiting MG. Minimally invasive fasciotomy in chronic exertional compartment syndrome and fascial hernias of the anterior lower leg: short- and longterm results. Mil Med. 2006;171(5):399-403. 
7. Detmer DE, Sharpe K, Sufit RL, Girdley FM. Chronic compartment syndrome: diagnosis, management, and outcomes. Am J Sports Med. 1985;13(3):162-170.

8. Drexler M, Rutenberg TF, Rozen N, et al. Single minimal incision fasciotomy for the treatment of chronic exertional compartment syndrome: outcomes and complications. Arch Orthop Trauma Surg. 2017;137(1):73-79.

9. Due J, Nordstrand K. A simple technique for subcutaneous fasciotomy. Acta Chir Scand. 1987;153(9):521-522.

10. Edmundsson D, Toolanen G. Chronic exertional compartment syndrome in diabetes mellitus. Diabet Med. 2011;28(1):81-85.

11. Finestone AS, Noff M, Nassar Y, Moshe S, Agar G, Tamir E. Management of chronic exertional compartment syndrome and fascial hernias in the anterior lower leg with the forefoot rise test and limited fasciotomy. Foot Ankle Int. 2014;35(3):285-292.

12. Fronek J, Mubarak SJ, Hargens AR, et al. Management of chronic exertional anterior compartment syndrome of the lower extremity. Clin Orthop Relat Res. 1987;220:217-227.

13. García-Mata S, Hidalgo-Ovejero A, Martinez-Grande M. Chronic exertional compartment syndrome of the legs in adolescents. J Pediatr Orthop. 2001;21(3):328-334.

14. Hutchinson MR, Bederka B, Kopplin M. Anatomic structures at risk during minimal-incision endoscopically assisted fascial compartment releases in the leg. Am J Sports Med. 2003;31(5):764-769.

15. Leversedge FJ, Casey PJ, Seiler JG, Xerogeanes JW. Endoscopically assisted fasciotomy: description of technique and in vitro assessment of lower-leg compartment decompression. Am J Sports Med. 2002;30(2):272-278.

16. Lohrer H, Nauck T. Endoscopically assisted release for exertional compartment syndromes of the lower leg. Arch Orthop Trauma Surg. 2007;127(9):827-834.

17. Lohrer H, Nauck T, Lohrer L. Endoscopic-assisted release of lower leg chronic exertional compartment syndromes: results of a systematic literature review. Sports Med Arthrosc. 2016;24(1):19-23.

18. Micheli LJ, Solomon R, Solomon J, Plasschaert VF, Mitchell R. Surgical treatment for chronic lower-leg compartment syndrome in young female athletes. Am J Sports Med. 1999;27(2):197-201.

19. Mubarak SJ, Owen CA. Double-incision fasciotomy of the leg for decompression in compartment syndromes. $J$ Bone Joint Surg Am. 1977;59(2):184-187.

20. Ota Y, Senda M, Hashizume H, Inoue H. Chronic compartment syndrome of the lower leg: a new diagnostic method using near-infrared spectroscopy and a new technique of endoscopic fasciotomy. Arthroscopy. 1999;15(4):439-443.

21. Pedowitz RA, Hargens AR, Mubarak SJ, Gershuni DH. Modified criteria for the objective diagnosis of chronic compartment syndrome of the leg. Am J Sports Med. 1990;18 (1):35-40.
22. Qvarfordt P, Christenson JT, Eklöf B, Ohlin P, Saltin B. Intramuscular pressure, muscle blood flow, and skeletal muscle metabolism in chronic anterior tibial compartment syndrome. Clin Orthop Relat Res. 1983;179:284-290.

23. Raikin SM, Rapuri VR, Vitanzo P. Bilateral simultaneous fasciotomy for chronic exertional compartment syndrome. Foot Ankle Int. 2005;26(12):1007-1011.

24. Reinking MF. Exercise related leg pain (ERLP): a review of the literature. N Am J Sports Phys Ther. 2007;2(3):170180.

25. Roberts AJ, Krishnasamy P, Quayle JM, Houghton JM. Outcomes of surgery for chronic exertional compartment syndrome in a military population. J R Army Med Corps. 2015;161(1):42-45.

26. Rorabeck CH, Bourne RB, Fowler PJ. The surgical treatment of exertional compartment syndrome in athletes. J Bone Joint Surg Am. 1983;65(9):1245-1251.

27. Rorabeck CH, Fowler PJ, Nott L. The results of fasciotomy in the management of chronic exertional compartment syndrome. Am J Sports Med. 1988;16(3):224-227.

28. Schepsis AA, Gill SS, Foster TA. Fasciotomy for exertional anterior compartment syndrome: is lateral compartment release necessary? Am J Sports Med. 1999;27(4):430-435.

29. Schepsis AA, Martini D, Corbett M. Surgical management of exertional compartment syndrome of the lower leg. Longterm followup. Am J Sports Med. 1993;21(6):811-817.

30. Stein DA, Sennett BJ. One-portal endoscopically assisted fasciotomy for exertional compartment syndrome. Arthroscopy. 2005;21(1):108-112.

31. Styf JR, Körner LM. Chronic anterior-compartment syndrome of the leg. Results of treatment by fasciotomy. J Bone Joint Surg Am. 1986;68(9):1338-1347.

32. Tjeerdsma J. Outcome of a specific compartment fasciotomy versus a complete compartment fasciotomy of the leg in one patient with bilateral anterior chronic exertional compartment syndrome - a case report. J Foot Ankle Surg. 2016;55(5):1027-1034.

33. Turnipseed W, Detmer DE, Girdley F. Chronic compartment syndrome. An unusual cause for claudication. Ann Surg. 1989;210(4):557-563.

34. Verleisdonk EJMM, Schmitz RF, van der Werken C. Longterm results of fasciotomy of the anterior compartment in patients with exercise-induced pain in the lower leg. Int $J$ Sports Med. 2004;25(3):224-229.

35. Wallensten R. Results of fasciotomy in patients with medial tibial syndrome or chronic anterior-compartment syndrome. $J$ Bone Joint Surg Am. 1983;65(9):1252-1255.

36. Wittstein J, Moorman CT, Levin LS. Endoscopic compartment release for chronic exertional compartment syndrome: surgical technique and results. Am J Sports Med. 2010;38(8):1661-1666. 